\title{
Lusioersily
}

\section{The experimental evaluation and improvements of a novel thermal diode pre-heatsolar water heater under simulated solar conditions}

Smyth, M., Quinlan, P., Mondol, J. D., Zacharopoulos, A., McLarnon, D., \& Pugsley, A. (2017). The experimental evaluation and improvements of a novel thermal diode pre-heatsolar water heater under simulated solar conditions. Renewable Energy, NA, NA. https://doi.org/10.1016/j.renene.2017.12.083

Link to publication record in Ulster University Research Portal

\section{Published in:}

Renewable Energy

Publication Status:

Published online: 29/12/2017

DOI:

10.1016/j.renene.2017.12.083

\section{Document Version}

Author Accepted version

\section{General rights}

Copyright for the publications made accessible via Ulster University's Research Portal is retained by the author(s) and / or other copyright owners and it is a condition of accessing these publications that users recognise and abide by the legal requirements associated with these rights.

\section{Take down policy}

The Research Portal is Ulster University's institutional repository that provides access to Ulster's research outputs. Every effort has been made to ensure that content in the Research Portal does not infringe any person's rights, or applicable UK laws. If you discover content in the Research Portal that you believe breaches copyright or violates any law, please contact pure-support@ulster.ac.uk. 


\section{Accepted Manuscript}

The experimental evaluation and improvements of a novel thermal diode pre-heat solar water heater under simulated solar conditions

M. Smyth, P. Quinlan, J.D. Mondol, A. Zacharopoulos, D. McLarnon, A. Pugsley

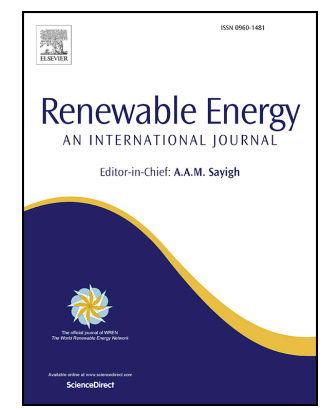

PII:

S0960-1481(17)31283-1

DOI:

10.1016/j.renene.2017.12.083

Reference: RENE 9580

To appear in: Renewable Energy

Received Date: 11 October 2017

Revised Date: 20 December 2017

Accepted Date: 22 December 2017

Please cite this article as: Smyth M, Quinlan P, Mondol JD, Zacharopoulos A, McLarnon D, Pugsley A, The experimental evaluation and improvements of a novel thermal diode pre-heat solar water heater under simulated solar conditions, Renewable Energy (2018), doi: 10.1016/j.renene.2017.12.083.

This is a PDF file of an unedited manuscript that has been accepted for publication. As a service to our customers we are providing this early version of the manuscript. The manuscript will undergo copyediting, typesetting, and review of the resulting proof before it is published in its final form. Please note that during the production process errors may be discovered which could affect the content, and all legal disclaimers that apply to the journal pertain. 
The experimental evaluation and improvements of a novel thermal diode

pre-heat solar water heater under simulated solar conditions

\author{
*M Smyth, P. Quinlan, JD Mondol, A. Zacharopoulos, D McLarnon and A Pugsley
}

*Centre for Sustainable Technologies, School of the Built Environment,

Ulster University, Newtownabbey BT37 OQB, N. Ireland.

Tel: ++44(0)2890368119, Fax: ++44(0)2890368239, e-mail: m.smyth1@ulster.ac.uk

\begin{abstract}
This paper presents the development through experimental performance characterisation of a pre-heat Integrated Collector Storage Solar Water Heater using a novel thermal diode operation to reduce ambient heat loss during non-collection periods. Using a solar simulator facility at Ulster University, the novel prototype pre-heat Mark IV unit was tested and evaluated. The concept has been designed and developed to be a sustainable pre-heat alternative to other types of solar water heating systems traditionally used in domestic hot water installations. The highest 6 hour collection efficiency was $36.17 \%$ under solar simulated conditions. The lowest system 'U' value was $0.98 \mathrm{Wm}^{-2} \mathrm{~K}^{-1}$ with no draw-off conditions. When the current prototype ICS units are compared with other conventional ICS systems, particularly in terms of thermal retention during non-collection periods, an improved performance is clearly demonstrated. The measured thermal losses were approximately $40 \%$ less than other similarly measured systems.
\end{abstract}

\title{
Keywords
}

ICSSWH, pre-heat, solar simulation, thermal diode

\section{Introduction}

The Energy Performance of Buildings Directive (EPBD) requires that Renewable Energy Systems (RES) are actively promoted in offsetting conventional fossil fuel use in buildings. A better appreciation of solar thermal system (STS) integration will directly support this objective, leading to an increased uptake in the application of renewables in buildings. Meeting building thermal loads will be primarily achieved through an extensive use of renewables, following standard building energy saving measures, such as good insulation or advanced glazing systems. Solar thermal systems are expected to take a leading role in providing the thermal energy needs, as they can contribute directly to the building heating, cooling and domestic hot water requirements.

Integrated Collector Storage Solar Water Heaters (ICSSWH) are simple, low cost solar devices and as such offer a suitable technology to partially meet the demands of the EPBD. The first ICSSWH systems consisted of exposed tanks of water left out to warm in the sun. Used on a few farms and ranches in the Southwest of the USA in the late 1800 s, they were reportedly capable of producing water hot enough for showering by the late afternoon on clear days [1]. The first solar water heater, manufactured commercially under the trade name 'The Climax Solar-Water Heater' was an ICSSWH patented in 1891 [2]. The development of these systems is detailed in Smyth et al [3] and more recently by Singh et al [4], along with their tendency to suffer significant ambient 
heat loss, especially at night-time and during non-collection periods. Many studies have been carried out focusing on the improvement of the thermal performance of ICSSWH systems, primarily during night operation [3][4]. Double vessel configurations offer an interesting solution to mitigating this problem.

Kalogirou [5] presents work conducted on a double vessel ICS design, examining the role and potential benefits of a smaller pre-heat vessel inserted in the collector cavity, directly above the main vessel. Quinlan [6] and Souliotis et al [7] optically analysed and experimentally studied a heat retaining ICS vessel design (based on De Beijer's [9] double vessel concept) mounted horizontally inside a stationary truncated asymmetric compound parabolic concentrating (CPC) reflector trough, combining 3 heat retaining enhancements previously researched. The thermal behaviour of the ICS system was compared to that of a Flat Plate Thermosiphonic Unit (FPTU) and experimental results showed that the ICS system was as effective during daily operation as it was during the night. Furthermore, the thermal loss coefficient during night-time operation was similar for the ICS system and FPTU. The current work presented in this study fully details the experimental characterisation of a pre-heat ICSSWH that utilises the novel thermal diode operation first presented by De Beijer [9] and enhanced by Souliotis et al [7][8]. This study enhances and further develops the work presented by Smyth et al [10] on the experimental performance characterisation of a pre-heat ICSSWH that utilises the same novel double vessel thermal diode operation but characterised using a bespoke thermal flux simulation test facility. Specific areas of improvement include methods of improving Heat Transfer Fluid contact with the absorbing surface, internal vapour and condensate control and external insulation.

\section{Description of the pre-heat thermal diode ICSSWH}

The conceptual pre-heat thermal diode ICSSWH is fabricated using 3 concentric cylinders; one transparent polymer outer cylinder forming the aperture and unit casing to protect the absorber vessel coating and reduce convective heat loss as well as defining the initial physical appearance of the unit; the other two metal vessels combine to create the integral collector/storage element. The outer vessel is the solar absorber (with an inner evaporating surface) and the inner vessel is the thermal store (with a condensing outer surface). The concentric design of the two vessels defines the annular cavity, crucial to the thermal diode operation. The generic system design and operation is illustrated in Figure 1.

The annular cavity is partially evacuated to a low pressure $(\sim 50 \mathrm{mb})$ and contains a small amount of a liquid/vapour PCM (phase change material) heat transfer fluid. This arrangement forms the thermal diode, promoting solar collection and thermal storage though phase change processes whilst reducing thermal losses by the vacuum insulation. During collection periods, solar radiation incident on the outer surface of absorbing vessel (the evaporator with selective coating) [pt 1] causes the PCM in contact with the vessel wall to evaporate at low temperature thus producing a vapour. The PCM vapour condenses on contact with the colder inner (storage) vessel (condenser) surface and the thermal energy is transferred to water store through latent heat exchange [pt 2]. Condensed PCM runs down the vessel wall to a reservoir at base of the annulus to repeat the cycle [pt 3] whilst the temperature of the store stratifies [pt 4]. During non-collection periods no evaporation takes place (no incident energy to drive the evaporation process) and because of the insulating layer created by the annulus, heat loss is reduced from the store [pt 5]. The annular cavity can use a range of liquid/vapour phase change materials 
(such as alcohols and commercial refrigerants), but water is the most cost effective and environmentally benign material and was the PCM of choice for this study.

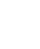

85

6

87

89

(1)

6
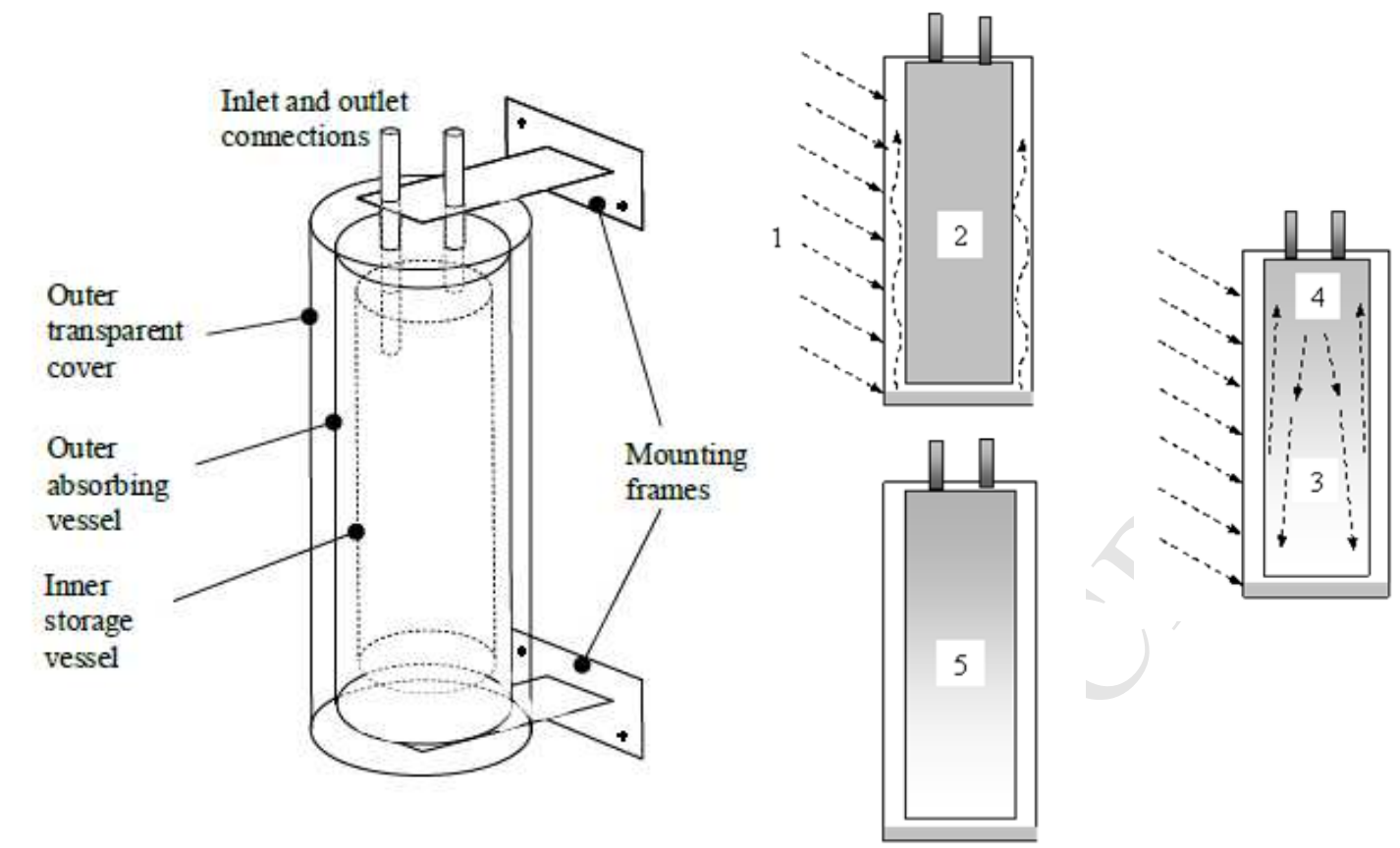

Figure 1: The initial conceptual design and operation of the pre-heat thermal diode ICSSWH

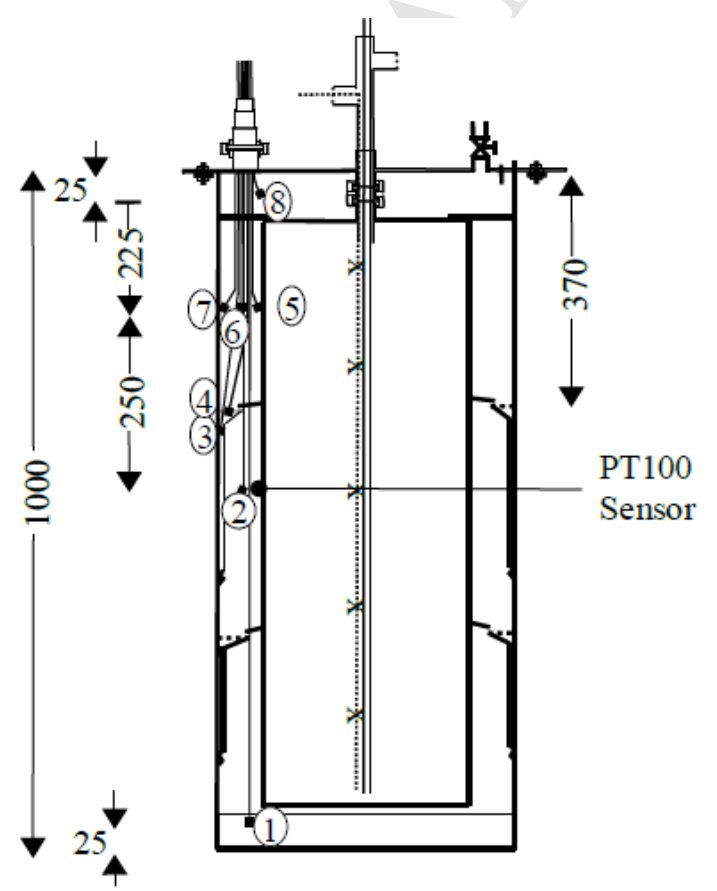

Figure 2: Cross section detail of the pre-heat thermal diode ICSSWH

A modified prototype version (Mark IV) of the pre-heat thermal diode ICSSWH was produced and evaluated using the solar simulator facility at Ulster University. This prototype was designed to increase the solar collection efficiency of previous 'base unit' designs developed by Quinlan [6]. By increasing the amount of Phase Change Material Heat Transfer Fluid (PCM HTF) volume in the annular cavity that was in direct contact with the heated absorbing (evaporator) surface of the outer vessel via a series of intermediate raised water reservoirs (pockets) that were longer and thinner than previous reservoir designs it was projected that an improved performance 
would result. In addition, adding a cowl configuration that was modified to permit upward flow of vapour but prevent downward flow of condensate (beyond the designated pocket) would also improve performance. Figure 2 depicts a cross sectional detail of the Mark IV thermal diode ICSSWH. The impact of these design modifications on the collection and cool down performance under solar simulated test conditions are presented. A number of different tests were conducted on the Mark IV prototype; exposed concentric cylinder design (MIV10), with outer transparent casing (MIV11) and outer transparent casing with insulation in the back 1/3 of the aperture cavity (MIV12). All variants had a starting annular cavity pressure at $\sim 30 \mathrm{mb}$ which represented at relatively low vaporising temperature and was achievable with the vacuum equipment in the laboratory.

The base unit consisted of two vessels, the outer vessel was $300 \mathrm{~mm} \varnothing$ (1m in length) and the inner vessel was $200 \mathrm{~mm} \varnothing(0.9 \mathrm{~m}$ in length). Both vessels were fabricated from $1.5 \mathrm{~mm}$ thick stainless steel sheet. Each vessel had a welded base with a flanging arrangement to allow for access and entry for monitoring instrumentation. The other unit variants were based the same dimensional and construction features used in the fabrication of the control unit, but incorporated the outer transparent casing and/or back insulation. The outer transparent casing was made from $1 \mathrm{~mm}$ thick PETG sheet with a stated transmissivity of 0.90 [11]. To increase radiation absorption, stove paint with absorptivity 0.95 [12] was applied to the outer vessel surface. The Mark IV had a mass of $24.16 \mathrm{~kg}$, thermal mass of $11.3\left(\mathrm{~kJ} / \mathrm{K}\right.$ ), outer vessel (absorbing) surface area of $1.08 \mathrm{~m}^{2}$ and inner vessel volume of 28.2 litres.

\section{Description of the experimental facility}

The experimental performance of the Mark IV variant pre-heat thermal diode ICSSWH concept was determined 

rotation symmetrical paraboloidal reflector to provide a light beam of high collimation. In order to achieve uniform distribution of light intensity on the test area, a lens is inserted in each lamp to widen the illumination of light. The characteristic combination of the reflector, lens and lamps ensures a realistic simulation of the beam path, spectrum and uniformity. The solar simulator control panel maintained the constant level light intensity automatically on the collector surface via a datum CMP6 Kipp and Zonen pyranometer (mounted at the centre of the test plane). T-type copper-constantan thermocouples were used to measure temperatures within the various units, including vessel, store and surface temperatures and ambient air temperature. Water storage temperatures were measured at eight locations to record the variation of water temperature within the inner store. Temperature, pressure and radiation measurements were recorded through a Delta T logging device linked to a PC, as shown in figure 3 and detailed in table 1.

Table 1: Details of experimental instrumentation

\begin{tabular}{|l|l|l|}
\hline \multicolumn{1}{|c|}{$\begin{array}{c}\text { Measured } \\
\text { Variable }\end{array}$} & \multicolumn{1}{|c|}{ Equipment } & \multicolumn{1}{c|}{ Range and Sensitivity } \\
\hline Temperature & $\begin{array}{l}\text { T-type copper-constantan } \\
\text { thermocouples }\end{array}$ & $\pm 0.5^{\circ} \mathrm{C}$ between 0 and $70^{\circ} \mathrm{C}$ \\
\hline Temperature & PT100 sensors & $\begin{array}{l} \pm 0.5^{\circ} \mathrm{C} \text { accuracy with an experimentally determined } \\
\text { standard deviation of } \pm 0.1^{\circ} \mathrm{C} .\end{array}$ \\
\hline Solar radiation & $\begin{array}{l}\text { CMP6 Kipp and Zonen } \\
\text { pyranometer }\end{array}$ & directional error up to $80^{\circ}$ at $1000 \mathrm{~W} / \mathrm{m}^{2}$ was $<20 \mathrm{~W} / \mathrm{m}^{2}$ \\
\hline Pressure & $\begin{array}{l}\text { Druck DPI 104 digital pressure } \\
\text { gauge }\end{array}$ & $\begin{array}{l}\text { Gauge pressure between }-1 \mathrm{bar}(\text { vacuum }) \text { to } 20 \mathrm{bar} \text { at } \\
0.05 \% \mathrm{FS}( \pm 10 \mathrm{mbar}) .\end{array}$ \\
\hline Pressure & $\begin{array}{l}\text { Danfoss MBS 33-2421-3AB05 } \\
\text { pressure transmitter }\end{array}$ & $\begin{array}{l}\text { Output of } 4-20 \mathrm{~mA} \text { and an absolute pressure range } 0 \text { to } \\
25 \text { bar }\end{array}$ \\
\hline
\end{tabular}

\section{Description of the experimental procedure}

The collection and thermal retention performance characteristics for all units were determined under solar simulated conditions. System performance characterisation was based on BS ISO 9459-5:2007 [13] applied to indoor conditions and whole-system testing. No thermal storage draw off was performed during any of the tests in this presented work. The tests were conducted over time periods of 6 to 24 hours in order to determine the daily collection efficiency (6 hours solar simulator exposure with an average solar intensity of $\sim 800 \mathrm{~W} / \mathrm{m}^{2}$ ) and an 18 hour cool down period to determine thermal retention. At the beginning of each experiment the inner vessel was re-filled and the test started with stable ambient temperatures and uniform tank temperatures.

Figure 4 shows the prototype Mark IV rig prior to exposure. The collection phase started when the simulator was switched on and a 30 minute warm up period elapsed. The prototype and test facility were then monitored for six hours after which the simulator were turned off. The cool down phase started immediately after simulator switch off and lasted for a further 18 hour period. Test information from the data logger was then downloaded for analysis. 


\section{Analysis methods}

where

Figure 4: Images of the Mark IV unit under solar simulator test conditions

The performance of each was experimentally determined from the data retrieved from the extensive testing programme. The thermal store, inner cavity/annulus and external environment in and around the collector aperture were examined during testing to define the system characteristics. The thermal store characteristics were retrieved from the average and normalised vessel temperatures and stratification during collection and cool down phases to create lumped collection and thermal retention efficiencies and develop the hypotheses for heat transfer mechanisms into and within the thermal store. The annulus characterisation used measured temperature and pressure variables taken during the collection and cool down phases, allowing review of temperature distribution and analysis of the sensible and latent heat transfer mechanisms taking place. The external environment is not characterised independently but as part of the characterisations within the thermal store and annulus. The following equations and terms are used. Simulated solar energy incident on the aperture area over the test period,

$$
\mathrm{G}_{\mathrm{ave}}=\left(\int_{\mathrm{t}_{\text {end }}}^{\mathrm{t}_{\mathrm{start}}} \mathrm{I}(\mathrm{t}) d t\right) / \Delta \mathrm{t}
$$

Experimentally measured temperatures were used to calculate average water temperatures in the thermal store volume $\left(\mathrm{T}_{\mathrm{av}}\right)$. The average start temperature $\left(\mathrm{T}_{\text {initial }}\right)$ and average end temperature $\left(\mathrm{T}_{\text {end }}\right)$ were determined during the collection phase using the recorded water temperatures in the thermal store at the beginning and end of collection period. Thermal energy collected $\left(\mathrm{Q}_{\mathrm{col}}\right)$ by the unit was determined by

$$
\mathrm{Q}_{\mathrm{col}}=\mathrm{mc}_{\mathrm{p}}\left(\mathrm{T}_{\text {end }}-\mathrm{T}_{\text {initial }}\right)
$$




$$
\eta_{\mathrm{col}}=\left(\frac{\mathrm{Q}_{\mathrm{col}}}{\mathrm{Q}_{\text {incident }}}\right) \times 100
$$

The collection efficiency varies depending on the collection time period used therefore during evaluation it was measured over a 6 hour period unless otherwise specified. Thermal stratification within the store is characterised by a stratification index $(\sigma)$ calculated using equation (5) [14]

$$
\sigma=\frac{\left(T_{a v, t}-T_{a v, b}\right)}{\left(T_{a v, t}-T_{a v, b}\right)_{s t a r t}}
$$

where $\mathrm{T}_{\mathrm{av}, \mathrm{t}}$ and $\mathrm{T}_{\mathrm{av}, \mathrm{b}}$ are the average thermal store temperatures within the top 1/5 and bottom 1/5 storage volumes and $\left(\mathrm{T}_{\mathrm{av}, \mathrm{t}}-\mathrm{T}_{\mathrm{av}, \mathrm{b}}\right)_{\text {start }}$ is the temperature difference between the top $1 / 5$ and bottom $1 / 5$ storage volumes at the beginning of the collection phase. A de-stratification time constant measured as the time it takes for the stratification index $\sigma$, to decrease to 0.3679 of its initial value, is used to measure de-stratification during the cool down period. Thermal retention efficiency $\left(\eta_{\text {ret }}\right)$ is determined by

$$
\eta_{\text {ret }}=\left(\frac{\mathrm{m} \times \mathrm{c}_{\mathrm{p}}\left(T_{\text {final }}-T_{\text {amb }}\right)}{\mathrm{m} \mathrm{X} \mathrm{c}_{\mathrm{p}}\left(T_{\text {initial }, c}-T_{\text {amb }}\right)}\right) \times 100
$$

where $T_{\text {initial,c }}$ is the average temperature at the start of the cool-down period, $T_{\text {final }}$ is the average temperature at the end of the cooling period and $\mathrm{T}_{\mathrm{amb}}$ is the average ambient temperature throughout the cool-down phase. The system heat loss coefficient also known as the system 'U' value was calculated from equation (7) [15]

$$
U_{\text {system }}=\frac{m c_{\text {system }}}{A_{\text {unit }} \Delta t} \ln \left(\frac{\left(T_{\text {initial }, c}-T_{\text {amb }}\right)}{\left(T_{\text {final }}-T_{\text {amb }}\right)}\right)
$$

where $\mathrm{mc}_{\mathrm{system}}$ is the thermal mass of the system based on the mass and specific heat capacity of the individual units and $\mathrm{A}_{\text {unit }}$ is the surface area of the outer vessel. All monitoring instrumentation has an associated experimental accuracy as presented in table 1.

\section{Results and Discussion}

Mark IV under solar simulation evaluated the base thermal diode ICSSWH concept at 30mb inner operating pressure as a bare unit (MIV10), a transparent cover (MIV11) and added insulation within the cover (MIV12). The 6 hour collection efficiencies for MIV10 and MIV12 under solar simulated test conditions where 29.39\% and $36.17 \%$, respectively. This was a marginal increase in collection performance and poor in overall terms. However, this work focuses on the importance of certain system features and subsequent designs have built upon this early work, resulting in even better collection efficiencies. Collection efficiencies, normalised average store 
and annulus temperatures for the current work are shown in figures 5, 6, 7 and 8 , respectively. The store thermocline development, store stratification index, system ' $U$ ' values and retention efficiencies for MIV10 and MIV12 are shown in figures 9,10 and 11, respectively.

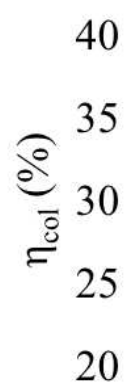

20
36.17
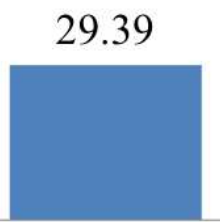

MIV 10

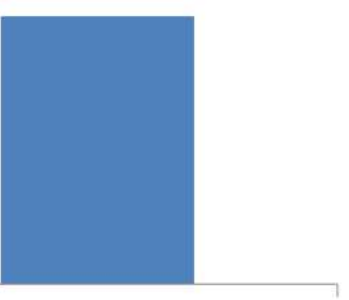

MIV 12
Figure 5: The 6 hour collection efficiencies for MIV10 and MIV12 under solar simulated test conditions

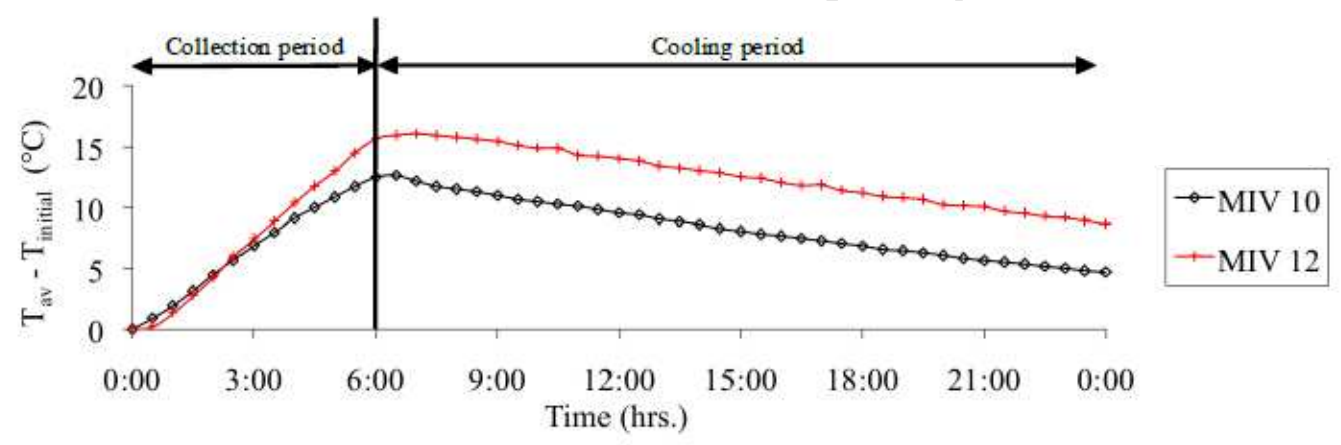

Figure 6: Normalised average vessel store temperature for MIV10 and 12 during a 6 hour collection period and 18 hour cool down period under solar simulated and indoor ambient test conditions

As shown in figure 5 (based on temperatures shown in figure 6), the 6 hour collection efficiency under the solar simulator for MIV12 was $36.17 \%$ representing an increase of $23 \%$ over MIV10 due to the addition of 50mm back insulation and transparent cover. Figure 7 illustrates the annulus temperatures and pressure for selected Mark IV tests over a 6 hour collection period under solar simulation test conditions. From the initial starting annulus pressure of $\sim 30 \mathrm{mb}$, a small rise of $50 \mathrm{mb}$ over the test period was observed due to the vapour creation in the annulus. On the test end, the pressure was measured and in all cases was back to the starting pressure indicating a hermetic seal was still present and all thermal measurements were due to system operation.

The inclusion of back insulation and transparent cover are crucial in achieving the desired evaporation and condensation cycle. Whilst the thermal diode will operate in retaining heat during non-collection periods, unless the all-important saturation temperature is achieved, the majority of heat transfer during the collection period will be primarily through radiation. This is evidenced by the temperatures measured by sensor PT100 3 which is located in the upper raised pocket (on the evaporator surface). In figure 7 - MIV10, the temperature at sensor PT100 3 is almost constant at the latter stages of the test whilst in MIV11, the temperature at sensor PT100 3 is still increasing with a slight dip at the 5 hour mark. In MIV12, the drop in temperature at sensor PT100 3 is more 
pronounced and circled in more detail in figure 8 . At the $4+$ hour mark water in the pocket has completely evaporated into the annulus but as condensate from the inner vessel starts to run back into the pocket, the temperature starts to drop until it reaches evaporation temperature again, permitting more convective heat transfer. A cover and some form of back insulation are therefore necessary to permit the saturation temperature in the annulus to be attained. In the case of MIV12 this is around $38^{\circ} \mathrm{C}$ for the given pressure in the annulus. Further refinements through capillary materials and coatings, covers and segmentation should enhance this process bringing the evaporation and condensation cycle earlier resulting in better collection efficiencies.

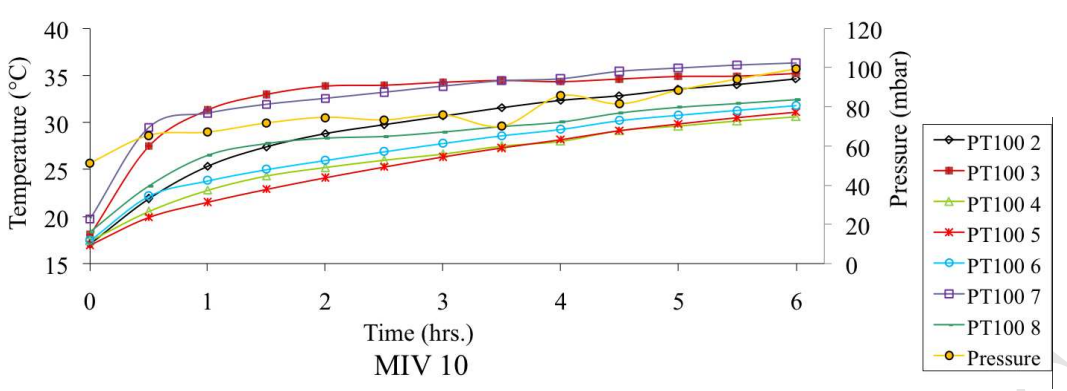

Figure 7: Annulus temperatures and pressure for Mark IV selected tests over a 6 hour collection period under solar simulation test conditions 


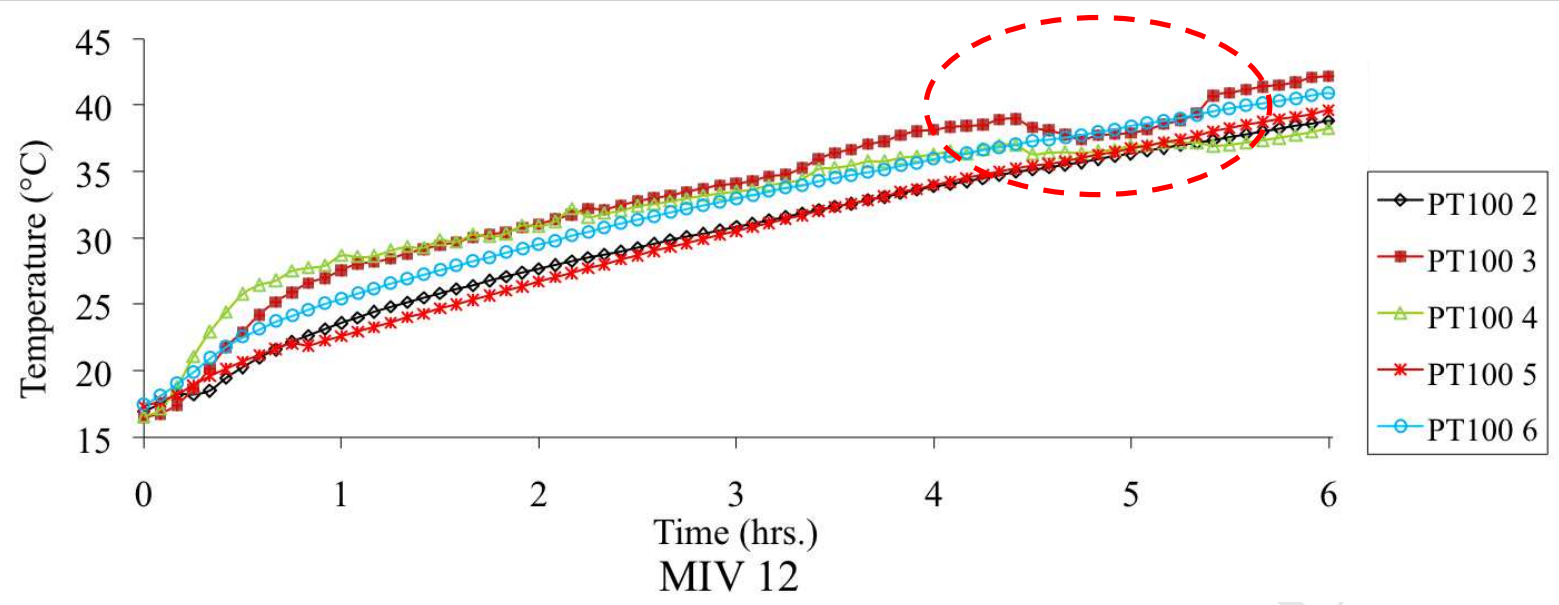

Figure 8: Annulus temperatures for MIV12 over a 6 hour collection period for selected sensors under solar

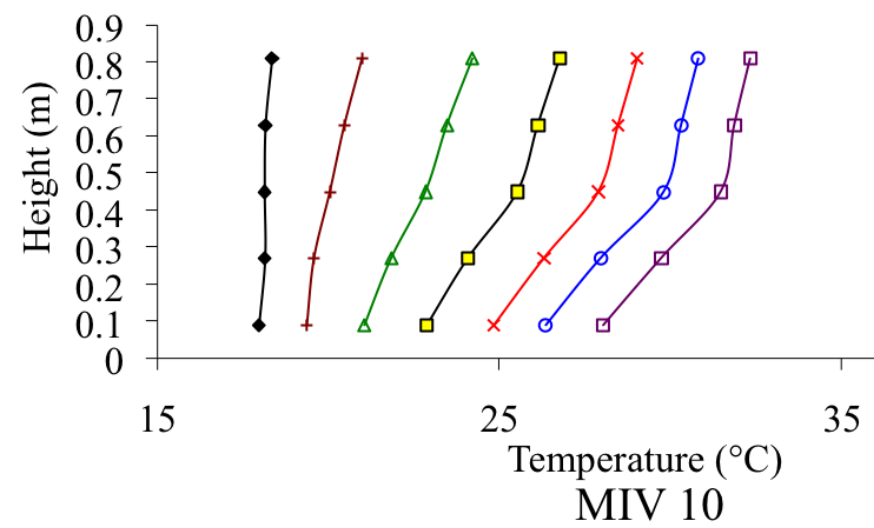
simulation test conditions (a) (a)

(n)

.

(1)

(2)

西

.

.

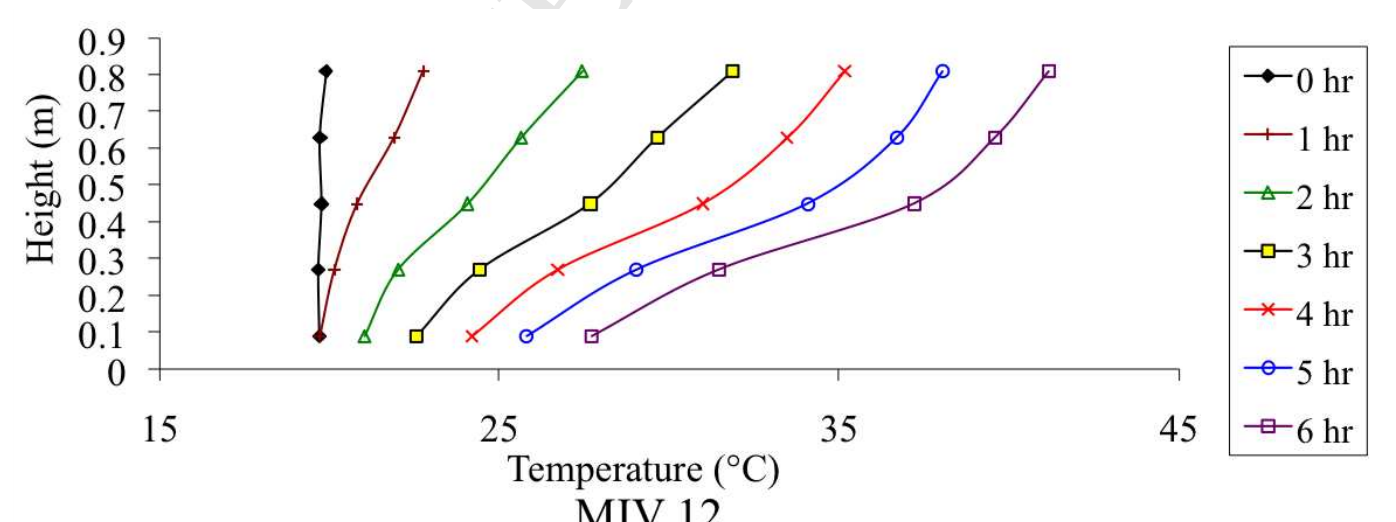

Figure 9: Hourly thermoclines during the collection period for MIV10 and MIV12 under solar simulated test conditions

Comparing the thermoclines for MIV10 and MIV12 (figure 9) and corresponding stratification index (figure 10) shows how the back insulation and transparent cover increases stratification in the thermal store. Comparing sensor PT100 8 in tests MIV10, MIV11 and MIV12 (figure 7) an $11^{\circ} \mathrm{C}$ increase in temperature at the top of the tank after 6 hours collection could be attributed to the inclusion of a transparent cover (MIV11) and a further $2^{\circ} \mathrm{C}$ due to the inclusion of the insulation in the back 1/3 of the aperture cavity (MIV12). 


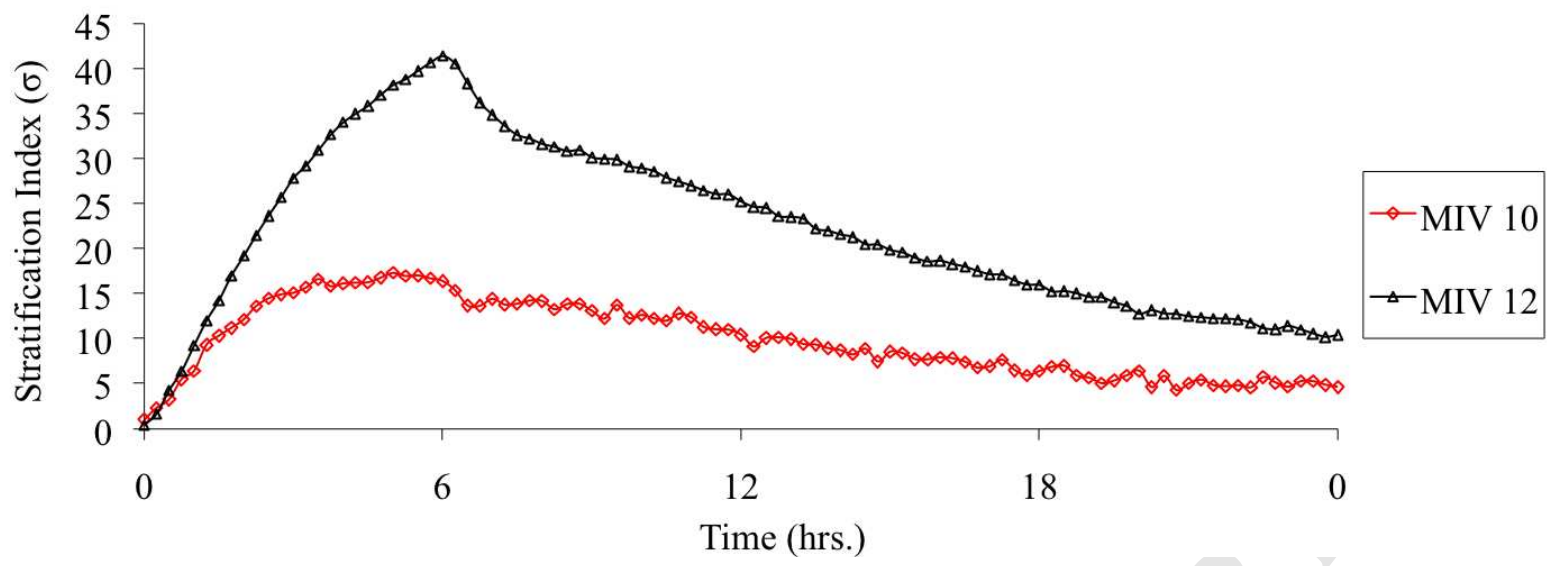

Figure 10: Stratification index for MIV10 and MIV12 over a 6 hour collection and 18 hour cool down period for

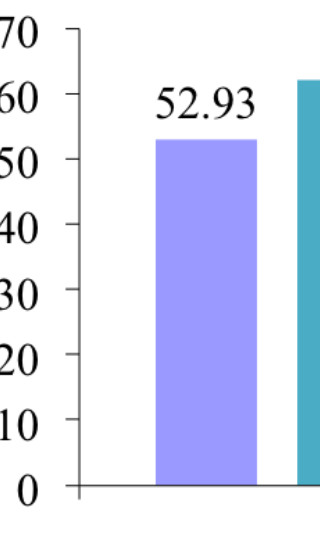

\section{Time (hrs.)}

\section{solar simulated and indoor ambient test conditions}



simulation test facility. Under testing, the highest 6 hour collection efficiency was 36.17\% and the lowest system ' $\mathrm{U}^{\prime}$ value was $0.98 \mathrm{Wm}^{-2} \mathrm{~K}^{-1}$ (MIV12) with no draw-off. The testing highlighted the importance of cover and insulation even in a thermal diode concept as temperatures need to be achieved and maintained to ensure the evaporation and condensation cycle. When the current prototype ICS units are compared with other conventional ICS systems, particularly in terms of thermal retention during non-collection periods, an improved performance is clearly demonstrated. The measured thermal losses were approximately $40 \%$ less than other similarly measured prototype systems, $1.05 \mathrm{WK}^{-1}$ (based on $1.08 \mathrm{~m}^{2}$ ) to $1.78 \mathrm{WK}^{-1}[4]$ and more typically greater than $5 \mathrm{WK}^{-1}$ for a commercial unit [16]. For comparison, the heat loss coefficient of a standard insulated tank is $0.9 \mathrm{WK}^{-1}$. The study concludes that the system performance is significantly improved when the heat retaining thermal diode feature is combined with elongated pockets and capillary matting, transparent cover, aperture cavity back insulation and transparent aperture cover. Through experimental and parametric evaluation, a unique pre-heat ICS solar water heating system has been designed, developed, analysed and presented. Significant steps have been made towards a potential commercial future, but in order to fully realise this goal, much more study is required. of Concept scheme. Thanks to support from COST Action TU1205 Building Integrated Solar Thermal Systems.

\section{NOMENCLATURE}

$\mathbf{A}_{\text {unit }} \quad$ surface area of unit $\left(\mathrm{m}^{2}\right)$

m mass of water $(\mathrm{kg})$

$\mathbf{m c}_{\text {system }}$ thermal capacity $(\mathrm{J} / \mathrm{K})$

$\mathbf{Q}_{\text {col }} \quad$ thermal energy collected (J)

$\mathbf{Q}_{\text {incident }}$ incident solar thermal energy (J)

T temperature $\left({ }^{\circ} \mathrm{C} / \mathrm{K}\right)$

$\mathbf{U}_{\text {system }} \quad$ system heat loss coefficient $\left(\mathrm{W} \mathrm{m}^{-2} \mathrm{~K}^{-1}\right)$

$\mathbf{U A}_{\text {system }}$ heat loss coefficient of system (W/K)

$\Delta \mathrm{t} \quad$ time (secs)

$\eta_{\text {optical }}$ optical efficiency 
amb average ambient temperature

av average water temperature

ave,heating average water temperature averaged over the heating period (K)

av,b average water temperature at bottom $1 / 5$ of vessel

av,t average water temperature at top $1 / 5$ of vessel

end average water temperature at end of heating period

final average final water temperature at end of cooling period

initial average initial water temperature

initial,c average initial water temperature at start of cooling period

ret heat loss retention

$$
\text { average water temperature at start of heating period }
$$

\section{REFERENCES}

[1] Butti K and Perlin J, 1981. A Golden Thread. Marion Boyars Publishers Ltd., London, UK

[3] Smyth M, Eames PC and Norton B, 2006. Integrated Collector Storage Solar Water Heaters. Renewable and Sustainable Energy Review, Vol. 10, Iss.6, pp 503-538

[4] Singh R, Lazarus IJ \& Souliotis M, 2016. Recent developments in integrated collector storage (ICS) solar water heaters: A review. Renewable and Sustainable Energy Reviews. Vol. 54, pp 270-298 [5] Kalogirou S, 2014. Solar Energy Engineering - Processes and Systems. Academic Press; 2nd Edition, ISBN:978012397270

[6] Quinlan P, 2010. The Development of a Novel Integrated Collector Storage Solar Water Heater (ICSSWH) Using Phase Change Materials and Partial Evacuation. PhD Thesis, University of Ulster, UK [7] Souliotis M, Quinlan P, Smyth M, Tripanagnostopoulos Y, Zacharopoulos A, Ramirez M, Yianoulis P, 2011. Heat retaining integrated collector storage solar water heater with asymmetric CPC reflector. Solar Energy, Vol. 85, No. 10, pp 2474-2487

[8] Souliotis M, Papaefthimiou S, Caouris YG, Zacharopoulos A, Quinlan, Smyth M, 2017. Integrated collector storage solar water heater under partial vacuum. Energy Vol. 139, pp 991-1002

[9] De Beijer HA, 1998. Product Development in Solar Water Heating. Proceedings of the $5^{\text {th }}$ World Renewable 504 Energy Congress, Florence, Italy, pp 201-204, Sept. 1998 [10] Smyth M, Quinlan P, Mondol JD, Zacharopoulos A, McLarnon D and Pugsley A, 2017. The evolutionary thermal performance and development of a novel thermal diode pre-heat solar water heater under simulated heat flux conditions. Renewable Energy Vol. 113, pp 1160-1167

508 [11] Anon. Veralite 200 Technical Data Sheet, www.iplast.be/ipb/Veralite 200 technical data sheet.pdf, 9th 509 August 2010.

510 [12] Norton B, 1992. Solar Energy Thermal Technology. Springer-Verlag, London, UK 
512 characterization by means of whole-system tests and computer simulation. BS ISO 9459-5:2007, British

513 Standards Institution, London, UK

514 [14] Gnafakis C \& Manno VP, 1989. Transient de-stratification in a rectangular enclosure. Transactions of the 515 American Society of Mechanical Engineers, Vol. 111, pp 92 -99

516 [15] Visser H and Van Dijk HAL, 1991. Test procedures for short term thermal stores. Kluwer Academic 517 Publishers, Dordrecht, Netherlands

518 [16] Faiman D, Hazan H, Laufer I, 2001. Reducing the heat loss at night from solar water heaters of the integrated collector-storage variety. Solar Energy Vol. 71, No. 2, pp 87-93 